REGARDS

SUR LECONOMIE ALLEMANDE

BULLETIN ECONOMIQUE DU CIRAC
Regards sur l'économie allemande

Bulletin économique du CIRAC

$89 \mid 2008$

Varia

\title{
Management social
}

KORTE Rolf-Jürgen, DRUDE Hartwig, Führen von

Sozialleistungsunternehmen. Konfessionelle Sozialarbeit und unternehmerisches Handeln im Einklang

\section{(2) OpenEdition}

Édition électronique

URL : http://journals.openedition.org/rea/3143

DOI : 10.4000/rea.3143

ISBN : 978-2-8218-0874-4

ISSN : 1965-0787

Éditeur

CIRAC

Édition imprimée

Date de publication : 1 décembre 2008

ISSN : 1156-8992

\section{Référence électronique}

« Management social », Regards sur l'économie allemande [En ligne], 89 | décembre 2008, mis en ligne

le 13 janvier 2009, consulté le 22 septembre 2020. URL : http://journals.openedition.org/rea/3143 ;

DOI : https://doi.org/10.4000/rea.3143

Ce document a été généré automatiquement le 22 septembre 2020.

(c) CIRAC 


\section{Management social}

KORTE Rolf-Jürgen, DRUDE Hartwig, Führen von

Sozialleistungsunternehmen. Konfessionelle Sozialarbeit und unternehmerisches Handeln im Einklang

\section{RÉFÉRENCE}

KORTE Rolf-Jürgen, DRUDE Hartwig, Führen von Sozialleistungsunternehmen.

Konfessionelle Sozialarbeit und unternehmerisches Handeln im Einklang, Duncker \& Humblot, Berlin, 2008, 296 p.

1 En Allemagne, les œuvres caritatives chrétiennes fondent leur existence sur l'art. 4 de la Loi fondamentale qui garantit la liberté individuelle de conscience et de religion. Mais à l'instar de toute entreprise, elles ne peuvent se soustraire aux impératifs économiques : il en va de leur survie. Prenant en considération les caractéristiques et besoins spécifiques des entreprises confessionnelles d'aide sociale, DRUDE, théologien et pasteur, et KORTE, économiste et chef d'entreprise, exposent les techniques de management du personnel, de marketing et de controlling applicables à ces structures, pour évaluer dans un second temps leurs perspectives d'avenir. La théorie résulte ici directement de la pratique, les auteurs ayant dirigé avec succès et pendant de nombreuses années la diaconie de Kästorf, située dans le Land de Basse-Saxe. (sh) 